RESIDENT

\& FELLOW

SECTION

Section Editor

Mitchell S.V. Elkind,

MD, MS

Michael Chen, MD

Thanh Nguyen, MD

Address correspondence and reprint requests to Dr. Michael Chen, Department of

Neurological Sciences, Rush

University Medical Center, 1725

West Harrison Street, Suite

1118, Chicago, IL 60612-3824

Michael_Chen@rush.edu

\title{
Emerging Subspecialties in Neurology: Endovascular surgical neuroradiology
}

In 1998, the World Federation of Interventional and Therapeutic Neuroradiology published fellowship guidelines for interventional neuroradiology (INR), specifying requirements for trainees with backgrounds in either neuroradiology or neurosurgery. ${ }^{1}$ In 2006, the Accreditation Council for Graduate Medical Education (ACGME) announced the revised program requirements in the United States for fellowship education in endovascular surgical neuroradiology (ESN). ESN was not only to be the new name in the United States for what was previously called interventional neuroradiology, but trainees with a neurology background were also included. ${ }^{2}$

ESN is defined by the ACGME as a clinical subspecialty for the diagnosis and treatment of neurovascular diseases using $\mathrm{x}$-ray fluoroscopy and angiography. Devices designed for the treatment of intracranial cerebral aneurysms, cerebral arteriovenous malformations, head and neck tumors, acute stroke, and intracranial stenosis have all gained Food and Drug Administration approval at varying levels, each with specific indications for therapy in the brain, head, neck, and spinal cord. Devices designed for extracranial and intracranial use include microcatheters, microguidewires, detachable coils, particulate and liquid embolic materials, clot retriever devices, stents, and balloons. Treatment options in interventional neuroradiology familiar to neurologists include extracranial and intracranial carotid revascularization and acute intraarterial thrombolysis (chemical or mechanical) for stroke. In recent years, there has been a greater awareness, development, and understanding of these treatment options, leading more neurologists to adopt an aggressive approach in consulting their neurointerventional colleagues. In addition, the evolution of the field has led some neurologists to pursue the necessary additional training to perform these procedures.

ACGME REQUIREMENTS FOR ESN FELLOWS WITH NEUROLOGY TRAINING The major ACGME requirements for neurology-trained fellows include the following 2 :

1) Completion of an ACGME-accredited residency in neurology

2) Completion of an ACGME-accredited 1-year vascular/stroke fellowship or a neurocritical care fellowship

3) Completion of 3 months of clinical experience within an ACGME-accredited neurologic surgery program

4) Completion of a preliminary year within neuroradiology during which the program will provide education and clinical experience to ensure that the fellow will receive the following training

a. A course in basic radiographic skills, including radiation physics; radiation protection; and the pharmacology of radiographic contrast materials acceptable to the program director where the neuroradiology training will occur

b. Performance and interpretation of a minimum of 50 diagnostic neuroangiograms under the supervision of a qualified physician (board-certified neuroradiologist, interventional neuroradiologist, or endovascular neurosurgeon with appropriate training)

c. Instruction in the use of needles, catheters, guidewires, and angiographic devices and materials

d. Recognition and management of complications of angiographic procedures

e. Understanding the fundamental noninvasive neurovascular imaging studies pertinent to the practice of endovascular

From the Department of Radiology (M.C.), New York Presbyterian Hospitals of Columbia and Cornell, New York; and Department of Radiology (T.N.), Centre Hospitalier de l'Université de Montréal, Quebec, Canada.

Disclosure: The authors report no conflicts of interest. 
surgery including CT/CTA, MR/MRA, and sonography of neurovascular diseases

HISTORY Egas Moniz, a Portuguese neurologist in the $1920 \mathrm{~s}$, is regarded as the pioneer who performed the first cerebral angiogram. ${ }^{3}$ At the time, the only intracranial anatomy that could be visualized was the ventricles with the introduction of air into the ventricular system. Imaging the living human brain was not considered possible at the time. Moniz began by giving large doses of bromides to patients orally, thinking that this sedating agent of atomic weight 80 would accumulate in the brain, and help opacify the brain parenchyma under fluoroscopy. The brain could not be visualized with this agent, even with injections directly into the carotid arteries. Further studies with different doses and techniques using decapitated heads eventually led to the use of iodine, which has an atomic weight of 127. In 1927, Moniz was able to distinctly visualize portions of the internal carotid artery in the Sylvian fissure, and he presented his work for the first time at the meeting of the Society of Neurology in Paris. ${ }^{3}$ He published his first book on cerebral angiography 4 years later, entitled Diagnostic des tumeurs cerebrals et epreuve de l'encephalographie arterielle. ${ }^{4}$

Neurointerventional therapies were not a natural extension from diagnostic cerebral angiography. These therapies were developed by physicians who were first and foremost clinicians, who dared to pioneer the riskier work with the goal of developing effective neuroendovascular therapies (Jean Raymond, MD, personal communication). Although neurologists in the United States have recently begun training in this field, it was neurologists outside of the United States who are regarded as among the original pioneers in interventional neuroradiology. Professor Luc Picard, who trained in both neuroradiology and neurology, performed his first set of cerebral embolizations in 1968. In 1982, he organized the annual meeting of the Working Group in Interventional Neuroradiology at Val d'Isère, France. He is a founding member of the World Federation of Interventional and Therapeutic Neuroradiology, of which he was the President from 1993 until 1995. Professor Georges Salamon, who trained in neurology in Marseille, was the first to create a national teaching program of neuroradiology, called "the course of Marseille." This course is considered to be the origin of clinical neuroradiology in France. In 1966, he created the INSERM Research Unit, the equivalent of NIH, under Professor Gastaut. This was a laboratory devoted to the anatomic basis of neuroimaging. ${ }^{5}$ Professor Auguste Wackenheim trained in neurology and radiology at Strasbourg, and he eventually became Chairman of Diagnostic Radiology in 1979. He saw himself not so much as a film reader but more of a thinker and initiator. $\mathrm{He}$ was one of the first on the continent to embrace and develop computers in radiology as well as CT. ${ }^{6}$ Professor Rene Djindjian, a neuropsychiatrist, worked with the neurosurgical service and Professor Houdart at the Lariboisiere Hospital, and he led the French contingent of the "American/English/French connection" in pursuit of unraveling the enigma of spinal vascular malformations (Luc Picard, MD, personal communication).

CONTROVERSIES IN ESN A unique and complicating feature of ESN is the overlapping interest in performing neurovascular interventions from several medical subspecialties, including neurology, neurosurgery, radiology, vascular surgery, and cardiology. Multiple editorials have highlighted the controversies over which type of physician is most appropriate to perform interventions such as carotid stenting and acute stroke thrombolysis. ${ }^{7,8}$ Some radiologists have expressed a concern that "INR is practiced today by an ever increasing number of practitioners not always optimally trained, as various specialists try to highjack INR resulting in its fragmentation." Intrahospital politics are sometimes exacerbated as new practitioners are viewed suspiciously by those who are more established.

However, as clinical research and practice in this field advance, it may become less relevant which specialist is performing the procedure. Philosophically, Picard believes that a fundamental interest in the human nervous system supersedes a physician's training background. With a group of highly trained physicians interested in the nervous system with an open spirit, with the goal being the best care of the patient, the specialty should continue to evolve in a positive direction.

VALUE OF THE NEUROLOGIST Some neurologists may have experienced the awkward situation of trying to make a clinical decision in the angiography suite while balancing this with the technical ability and judgment of the neurointerventionalist. Selection of patients eligible or ineligible for neurovascular interventions is not easy, even for physicians with neuroscience training. ${ }^{10}$ Difficult cases can strain this collaborative effort between neurologists and interventionalists and may magnify the differences in training between the two. Neurologists with ESN training have the ability to streamline care for patients with cerebrovascular disease and participate in clinical 
decision-making both inside and outside of the angiography suite. In addition, their broader exposure to cerebrovascular natural history and medical treatments during neurology training allows them to manage the patient along the continuum from admission, to intervention (if indicated), to discharge. This unique skill set for the endovascular neurologist has positive implications never before seen in advancing the care of patients with cerebrovascular disease.

PRACTICAL ISSUES FOR THE NEUROLOGIST The motivations driving neurologists to endovascular neuroradiology are both practical and personal. Picard was motivated by a field in medicine that was both logical and effective. Although he felt neurology to be logical, he did not find it very effective in the 1960s, whereas he felt neurosurgery to be too aggressive. Neuroradiology appeared to him poised to undergo immense development with a potential for what he describes as having "grand efficacy." Another endovascular neurologist states that his motivation to pursue additional training was to acquire the ability to provide a range of treatment options for his patients with cerebrovascular disease (Adnan I. Qureshi, MD, personal communication). Still others were motivated more by a sense of frustration with the lack of research in the area of endovascular therapies for acute ischemic stroke. They sensed that ESN-trained neurologists could contribute to the advancement of acute stroke therapies via a consortium of neurointerventionalists similar to the Thrombolysis in Myocardial Infarction study group, which has made great strides in cardiology research (Rishi Gupta, MD, personal communication).

The highest training standard should be applied to physicians interested in performing any neurovascular intervention because procedural complications can be disabling or fatal. ${ }^{11}$ Expertise in neurovascular anatomy, stroke pathophysiology, and neurodiagnostic and angiographic interpretation, combined with proficiency in catheter/device manipulation, is essential to developing the successful neurointerventionalist. Ideally, the year of vascular neurology training should be at an institution that treats a large volume of ischemic stroke with IV tissue plasminogen activator and intraarterial recanalization therapies (Rishi Gupta, MD, personal communication). While vascular neurology may be an acceptable route in preparation for ESN, some find neurocritical care training an important prerequisite for ESN training, particularly as it pertains to the periprocedural clinical care of the patient with subarachnoid hemorrhage or an acute stroke (Adnan I. Qureshi, MD, personal communication). These patients are often critically ill, and the ability to manage the airway, blood pressure, and raised intracranial pressure among other issues can only improve patient management. For the neurologist in ESN training, particular attention should be dedicated to interpretation of as many cerebral angiograms, brain CT scans, and brain MRI scans related to patient care as possible, since prior neurologic training may not have provided as much imaging exposure compared to a radiologist trainee. Three-dimensional visualization of cerebral blood vessels as they relate to the brain parenchyma and skull is another important skill that allows choosing the best views for catheter navigation and safe intervention.

Neurologists need to prepare themselves during training such that they can contribute clinical acumen in patient management as well as provide a clinically oriented perspective in neuroendovascular research. Active involvement in clinical research and writing papers to better understand the scientific process in anticipation of using one's endovascular training to design properly conceived clinical trials is recommended (Rishi Gupta, MD, personal communication). Compared to other interventional specialties such as cardiology, there is a relative paucity of trials in endovascular neuroradiology. Obstacles to high quality neuroendovascular research may relate to the lower volume of cases and the discomfort associated with randomizing patients. Residency training in neurologic programs tends to embrace research and clinical trial work, which should be cultivated as the neurologist develops a career in endovascular neuroradiology.

The decision by a young neurologist to pursue the additional years of ESN training must include some sense of what realistic practice options exist after finishing training. Recent federal policy changes in Medicare reimbursement have led hospitals to prioritize acute stroke care. Tertiary hospitals have more incentive now to acquire a JCAHO comprehensive stroke center designation, and neurointerventionalists play a critical role in helping centers achieve this certification. As a result of this momentum, opportunities currently are increasingly available for ESN-trained neurologists. A crucial issue for the endovascular neurologist in the initial job search remains being able to strike an acceptable balance between providing clinical care as a vascular neurologist, a neurointensivist, a neurointerventionalist, or 
some combination of the three. Of course, in any role, the local community and hospital further defines the role based on its needs, resources, and strengths.

Two career paths are often described that recently trained ESN neurologists have taken (Adnan I. Qureshi, MD, personal communication). The first, called a dual practice model, involves clinical management of patients with cerebrovascular diseases regardless of the need for interventional procedures. A practice, for example, may have one third of the patients requiring interventional procedures. The second model is more along the lines of a radiologist-consultant whereby the focus is exclusively interventional procedures and periprocedural management.

THE FUTURE A Society of Vascular and Interventional Neurology (SVIN) has recently formed, comprised largely of neurologists trained in ESN from around North America. It currently has about 150 members whose mission is to operate and represent a society interested in the innovative treatment of cerebrovascular and other neurologic diseases. Their aim is to promote cooperation, foster scientific research, raise awareness, and conduct teaching conferences for physicians and scientists interested in vascular and interventional neurology. This organization is not limited to interventionalists or neurologists and the society is actively recruiting new members. Interested persons can refer to the SVIN website at www.svineuro.org, where fellowship and job opportunities are listed. At this time, most training programs in the United States, even those led by neurosurgeons and neuroradiologists, seriously consider qualified neurologists for fellowship positions.

At the first annual SVIN meeting in Boston, Walter Koroshetz, deputy director of National Institute of Neurological Disorders and Stroke, addressed the question, "Why the neurologist?" $\mathrm{He}$ emphasized that a vascular or neurocritical care background is an essential aspect of training, as this is the expertise the neurologist contributes to a field with neuroradiologists and neurosurgeons. Other advice he offered:

1) Be wary of burnout.

2) Be generous and collaborate with others.

3) Get over the feeling that you are always right. C. Miller Fisher said he was wrong $90 \%$ of the time when he came to brain cutting.

4) Evidence is necessary because you need to know you are helping the patient. The NIH is interested in research that defines outcomes.

\section{ACKNOWLEDGMENT}

The authors thank Professor Luc Picard, Jean Raymond, MD, Adnan I. Qureshi, MD, and Rishi Gupta, MD, for their help with this article.

\section{REFERENCES}

1. Picard L, Negoro M. 1998 World Federation of Interventional and Therapeutic Neuroradiology Guidelines for Fellowship Training Programmes in Interventional Neuroradiology. Interventional Neuroradiol 1998;4: 195-197.

2. Available at: http://www.acgme.org/acWebsite/downloads/ RRC_prRev/163_422pr08_31_06.pdf

3. Doby T. Cerebral angiography and Egas Moniz. AJR Am J Roentgenol 1992;159:364.

4. Moniz E. Diagnostic des tumeurs cerebrals et epreuve de l'encephalographie arterielle. Paris: Masson; 1931.

5. ASNR Award Winners. AJNR Am J Neuroradiol 2006; 27:1597.

6. Wenz W. Obituary Prof Auguste Wackenheim, 19251998. Eur Radiol 1998;8:1500-1501.

7. Levy EI, Rinaldi MJ, Howington JU, et al. Should interventional cardiologists treat ischemic strokes? A global perspective. J Invasive Cardiol 2002;15:646-651.

8. Johnston SC. Who belongs inside the carotid arteries? Neurology 2005;64:188-189.

9. Available at: http://www.wfitn.org/documenti/ Std.Pract.WFITN.Venice.pdf

10. Findlay JM, Nykolyn L, Lubkey TB, et al. Auditing carotid endarterectomy: a regional experience. Can J Neurol Sci 2002;29:326-332.

11. Connors JJ III, Sacks D, Furlan AJ, et al. Training, competency, and credentialing standards for diagnostic cervicocerebral angiography, carotid stenting, and cerebrovascular intervention. Neurology 2005;64:190198 


\section{Neurology}

\section{Emerging Subspecialties in Neurology: Endovascular surgical neuroradiology Michael Chen and Thanh Nguyen \\ Neurology 2008;70;e21-e24 \\ DOI 10.1212/01.wnl.0000299086.22147.89}

This information is current as of May 21, 2008

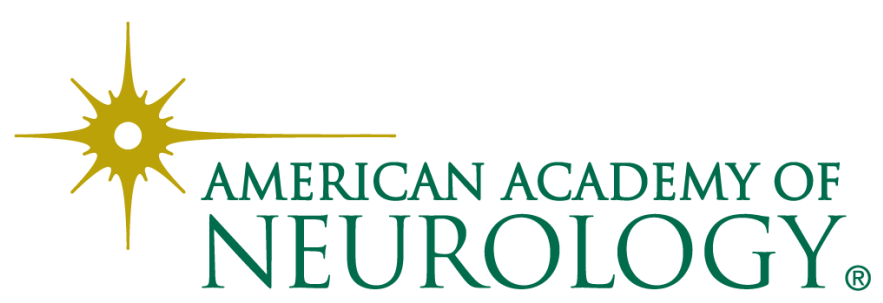




\section{Updated Information \& Services}

References

Citations

Subspecialty Collections

Permissions \& Licensing

Reprints including high resolution figures, can be found at: http://n.neurology.org/content/70/6/e21.full

This article cites 8 articles, 2 of which you can access for free at: http://n.neurology.org/content/70/6/e21.full\#ref-list-1

This article has been cited by 1 HighWire-hosted articles: http://n.neurology.org/content/70/6/e21.full\#\#otherarticles

This article, along with others on similar topics, appears in the following collection(s):

\section{All Cerebrovascular disease/Stroke}

http://n.neurology.org/cgi/collection/all_cerebrovascular_disease_strok e

All Education

http://n.neurology.org/cgi/collection/all_education

Arteriovenous malformation

http://n.neurology.org/cgi/collection/arteriovenous_malformation Other cerebrovascular disease/ Stroke

http://n.neurology.org/cgi/collection/other_cerebrovascular_disease_st roke

Stroke prevention

http://n.neurology.org/cgi/collection/stroke_prevention

Subarachnoid hemorrhage

http://n.neurology.org/cgi/collection/subarachnoid_hemorrhage

Information about reproducing this article in parts (figures,tables) or in its entirety can be found online at:

http://www.neurology.org/about/about_the_journal\#permissions

Information about ordering reprints can be found online:

http://n.neurology.org/subscribers/advertise

Neurology ${ }^{\circledR}$ is the official journal of the American Academy of Neurology. Published continuously since 1951, it is now a weekly with 48 issues per year. Copyright . All rights reserved. Print ISSN: 0028-3878. Online ISSN: 1526-632X.

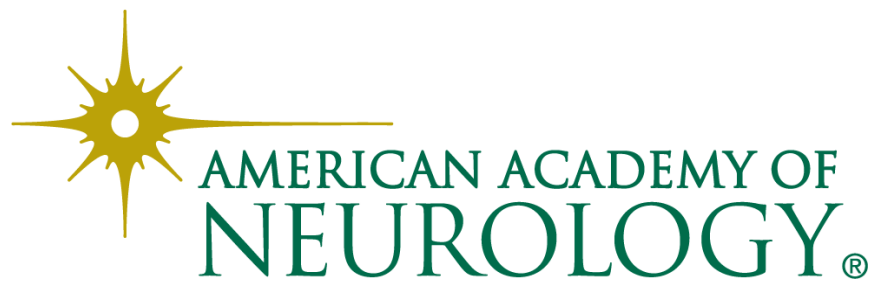

